Webology, Volume 17, Number 1, June, 2020

\begin{tabular}{|l|l|l|l|}
\hline Home & Table of Contents & Titles \& Subject Index & Authors Index \\
\hline
\end{tabular}

\title{
Web Self-efficacy: A Psychological Prerequisite for Web Literacy
}

\author{
Hamid Keshavarz \\ Assistant professor, Department of Information Science and Knowledge Studies, Shahid Beheshti \\ University, Tehran, Iran. ORCID: 0000-0002-5589-238X. Email: ha_keshavarz@sbu.ac.ir
}

Received January 25, 2020; Accepted June 20, 2020

\begin{abstract}
Initially, the present paper aims at conceptualizing self-efficacy as an important psychological construct put forth more than 30 years ago by the most cited living psychologist, Albert Bandura. The concept has been tested and confirmed by many researchers in different disciplines and recently in the web environment. Furthermore, web literacy is also a significant skill that is of high importance in using web resources. Using evaluation criteria traditionally applied to print sources combined with new strategies for making sense of contents in hypertext and multimedia formats is considered the main skill in web literacy. However, the two concepts of self-efficacy and web literacy have not been given full consideration in related literature jointly. Such subject areas as adaptation and application of information technologies; information-related skills and research competencies are dependent on users' psychological characteristics such as self-efficacy in the web environment. Following a conceptualization related to the concept of web selfefficacy, some of the most important types of it ranging from computer to research self-efficacy are explored at the end of the paper.
\end{abstract}

\section{Keywords}

Self-efficacy; Web self-efficacy; Web literacy; Information literacy; Cognitive-Social Theory

\section{Introduction}

New educational ideas are based on the constructivist paradigm, which highly values information because it is considered the basis of knowledge formation (Pajares, 1997; Arslan, 2017). Therefore, skills for dealing with information are considered an essential factor for survival in 
the current century. Information literacy has been defined as constructing a well-defined information need, finding the required information, assessing obtained information, and proper use of information in the desired context (Ata, 2011; Ata \& Baran, 2011; Cakmak, 2010). Users with information literacy skills would know how to learn, how knowledge is formed, and how information is found and used. The fact that information literacy is one of the essential skills for lifelong learning and one must always seek to gain and increase information literacy has been greatly emphasized. In its specific sense, information literacy comprises of media literacy, network literacy, computer literacy, and web literacy (Savolainen, 2002), since most information is obtained through computers, the internet, and the web recently (Figure 1).

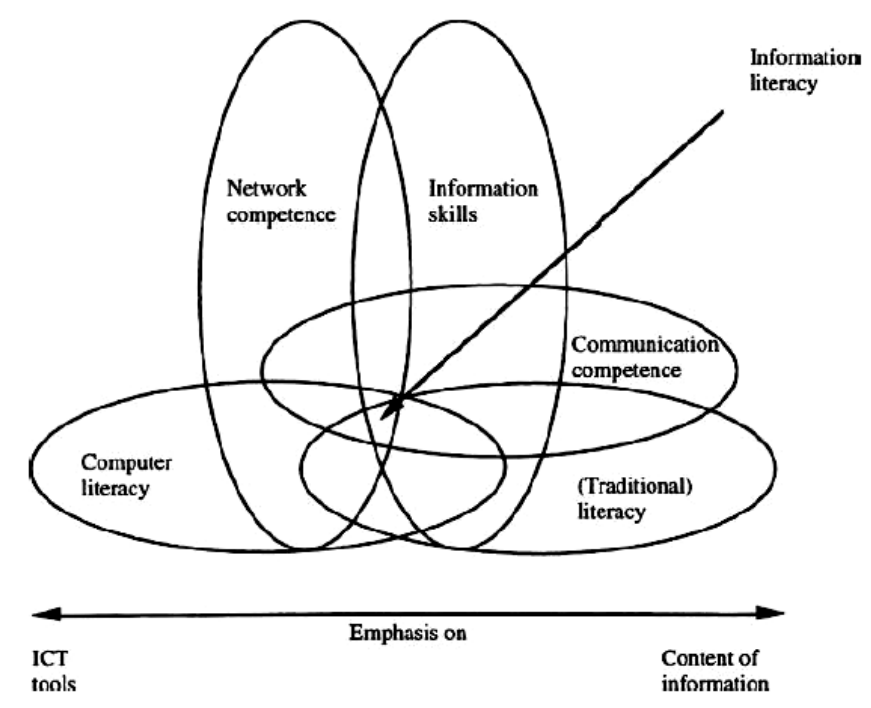

Figure 1. Various types of literacy and information environments (Savolainen, 2002)

Furthermore, web literacy as a new concept derived from information literacy is a highly important competency for independent study, self-regulated learning, lifelong learning, and social development on the web setting. Therefore, web literacy does not end with teaching skills as it also includes providing learning experiences for using information skills. According to Kurbanoglu (2003) the individuals with the ability to search, judge, analyze, combine, produce and share information on the web are active members of the information community. Different authors have addressed the significance of information and web literacy in various ways over the past two decades. However, information and web literacy can be conditioned by psychological characteristics as many researchers mentioned in their studies (e.g. Kurbanoglu, Akkoyunlu \& Umay, 2006; Ross, Perkins, and Bodey, 2013).

The current paper attempts to describe the significance of human psychological characteristics in web usage especially the psychological construct of self-efficacy and its types. In other words, 
self-efficacy is considered as one of the prerequisites of web literacy and the relationship between the two concepts is investigated.

\section{Psychological features in the web environment}

Lack of theorizing and applying the findings of the humanities, social and behavioral sciences in the web environment has been addressed in the related literature for many years. One of the major ideas in the field of social psychology, which has been tested extensively over the past few decades, is the "cognitive-social theory" (Bandura, 1986), first presented by Albert Bandura in 1977. For the sake of this theory, Bandura is considered the fourth influential theorist and psychologist in psychology after Skinner, Freud, and Piaget (Haggbloom, 2002). Besides, he is named as the most prominent and prestigious alive theorist in the subject area of psychology (Haggbloom, 2002).

In the view of social-cognitive theory, the personality structure of a human is dynamic, the understanding of which requires attention to the cognitive processes. Bandura provides a view of human behavior in which individuals' beliefs of themselves are the key elements of control and activity, and individuals perceive themselves as both the product and producer of their environment and social system. In social-cognitive theory, human behaviors are oriented and persist over time with intrinsic stimuli that are rooted strongly in cognitive activities (Bandura, 1986). It focuses on the social roots of the behavior and importance of cognitive processes in shaping personality, emotion, and practice. This theory, which is considered a negative reaction to the previous theories like psychotherapy refers to the variability of human behavior in different situations.

In this theory, attention has been paid to concepts such as self -belief, self-regulation, and selfefficacy, each of which is worth studying. Among these concepts, self-efficacy has been widely welcomed by researchers in various disciplines as well as by Bandura himself $(1977,1986,1993$, 2001). Self-efficacy is the judgment of individuals regarding their abilities to organize and perform a set of behaviors for different performances (Bandura, 1986, 1993).

This concept has been considerably investigated in various disciplines dealing with human behavior on the web especially in social psychology, the most recent of which is research by Rodon and Meyer (2018). Since this concept is one of the important constructs of psychology and behavior, it is worthy of attention especially in the field of web environment and research. Before addressing the concept of web self-efficacy, this concept is examined along with the other similar concepts, such as competence and ability. 


\section{Competency, ability, and self-efficacy}

Self-efficacy is one of the fundamental components of the competency of people from all walks of life. Competency in general means that individuals can adapt appropriately to their appointed environment over time to realize goals, which will result in proportionality, coherence, and performance of work proportionately based on existing abilities (Savolainen, 2002).

Especially in the current era in which the application of networks and information technologies have been extensively common, competency is considered more important than ever, so that network competency has been proposed for it (Jääskeläinen \& Savolainen, 2003). This competency is regarded as one of the requirements of contemporary users and is important for filling digital skills and turning into information society citizens.

Competency has two dimensions: knowledge and skill (Figure 2). Knowledge refers to a previous understanding regarding different circumstances and skill means the ability to use knowledge consciously and even unconsciously and practically in the operational contexts. Skill is a technical aspect of competency and implies how to perform specific jobs. From this perspective, a competent person has several features: knowledge (the necessary intellectual properties), skill (how to do an activity), and ability (execution and sensitivity to requirements of the working context).

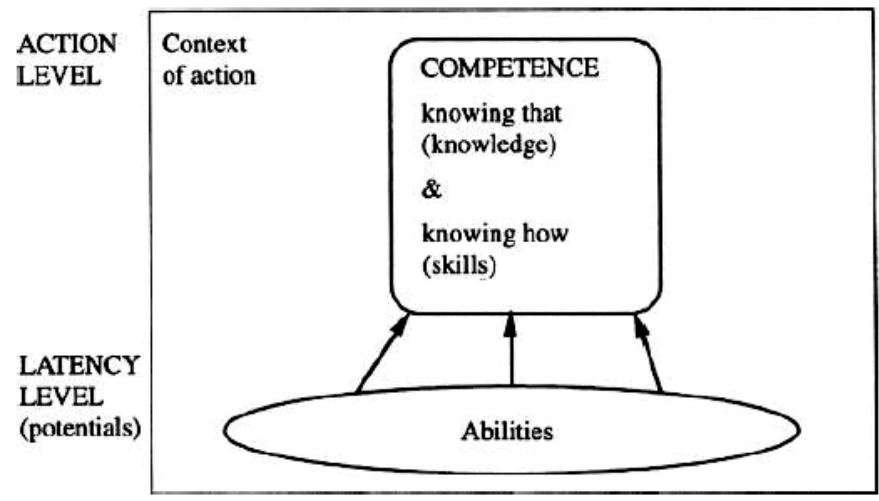

Figure 2. Ability, knowledge and competency to perform activities (Savolainen, 2002)

In this definition, the ability is used as intrinsic, intellectual, and physical resources for daily and professional life. Bandura considers ability as a productive capability in which cognitive, social, motivational, and behavioral skills are organized and used to achieve different goals (Bandura, 1993).

Abilities are the intrinsic resources rooted in the intellectual and physical areas of the individual and used in everyday life. Competency implies one's power for performing works appropriately based on his intrinsic ability. Thus, competency is perceived and defined as the application of ability in a social context through knowledge resulting from study and experience (Jääskeläinen 
\& Savolainen, 2003). According to Savolinen (2002) competency is a set of related abilities including knowledge and skills that enables one to perform in a job or situation in an effective manner.

Jääskeläinen and Savolinen (2003) believe that competency is an appropriate way for the combination of knowledge about what to do and how to do in action. Self-efficacy perceptions are developed based on individuals' competencies for performing specific activities. Selfefficacy is not just associated with the competency, but also it denotes one's judgment about his abilities concerning his competency.

\section{Self-efficacy: Concept and sources}

Self-efficacy is a determinant factor in human achievements and behaviors (Ata \& Baran, 2011) and considerably influences one's interest, pleasure, and success (Bandura, 1986; Adalier \& Serin, 2012). In short, self-efficacy means that what a person performs in a series of behavior depends on the beliefs about the success of such an action. These beliefs depend on the individual's knowledge of what to do and how to do, which is the same as competency. Selfefficacy is the judgment of individuals from their abilities to organize and perform a set of behaviors for different performance (Kurbanoglu, 2003; Kurbanoglu, Akkoyunlu \& Umay, 2006).

Individuals' information on their performance contributes to the formation of such a judgment and affects the choice, integration, interpretation, and gathering of information on subsequent judgments of self-efficacy. Self-efficacy is a dynamic set of self-belief that relates to specific functional domains and interacts extensively with other individuals, behaviors, and environmental factors (Cabaroglu, 2014).

Importantly, self-efficacy beliefs affect motivational and self-regulatory processes through five aspects of choosing options, effort, perseverance, flexibility, anxiety, and concern for difficult tasks (Pajares, 1997). High self-efficacy creates a feeling of calm in the face of difficult issues and activities (Tella, 2009). High self-efficacy and negative outcomes are also probable, like the person who is talented in an area that does not perform an activity for social reasons. Bandura distinguishes between these output expectations and self-efficacy. He distinguishes between the outcomes of work and self-efficacy (Bandura, 1997). Self-efficacy is considered as dependent on the outcomes. Self-efficacy with an impact on the endeavor and perseverance causes a variety of outcomes. It even increases memory performance by strengthening perseverance (Pajares, 1997). High self-efficacy causes a higher application of metacognitive and cognitive strategies (Ata, 2011). Some consider self-efficacy as the facilitator of cognitive processes that lead to more use of meta-cognitive strategies and better performance. 
Laboratory research indicated that individuals with high self-efficacy are more interested in work, more hard-working, more resistant against problems, and have better performance compared to individuals with low self-efficacy. If self-efficacy can influence motivation, emotion, and human behavior in such a way, it is worth further investigation and research. Bandura believes that self-efficacy beliefs influence individuals' motivation through influencing the goals (Bandura, 2001). Individuals who do not trust in their skills, reduce their endeavor when facing the problems, or essentially leave the work.

In the view of Bandura (1993), individuals with self-evaluation assess their experiences and intellectual processes. What people know, their skills, and what they have previously done are not always good predictors of their future achievements since the beliefs of their capabilities influence their behavioral approaches. Thus, the way of behavior is highly influenced by individuals' beliefs about their capabilities, and they are better predicated than previous performance. Self-efficacy is originated from four sources (Figure 3):

- Mastery experience (past performance);

- Vicarious experience (succession experience)

- Verbal persuasions (verbal conviction)

- Physiological states (emotions).

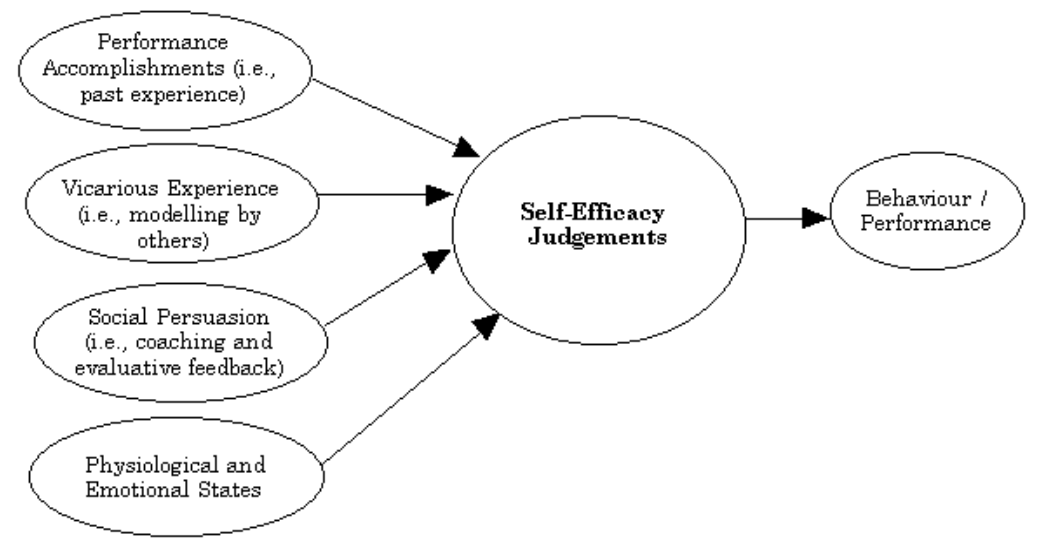

Figure 3. Sources of self-efficacy (Bandura, 1993)

The first source, which is the same as the past and successful experiences of a person in doing a job, is the most important factor in self-efficacy because it is the most reliable proof of success in doing things. The second factor or observation of a pattern that successfully performs a job is social comparison. The formation of self-efficacy beliefs depends on the ability of the individuals being compared with the other persons doing similar jobs. The third factor, or the credibility and competence of the encouraging person, is also an important issue. Such encouragement is something beyond non-serious and non-principled encouragement. It must be realistic to avoid misleading the recipient, which leads to a reduction in the self-efficacy and 
credibility of the individual. Mental states in doing tasks like fear, anxiety, confusion, or worry influence the level of success and considered the last component of self-efficacy.

\section{Self-efficacy and practical areas on the Web}

Many factors affect web self-efficacy, the most important of which is gender and educational level. While some do not believe that one of the main effective factors on self-efficacy in general and web self-efficacy, in particular, is the gender, some research considers differences in selfefficacy resulting from the gender (Malliari, Korobili \& Togia, 2012). Also, self-efficacy in educational systems and learning is a determinant factor for doing affairs and compatibility with the environment, and influence how to do jobs and managing it. Since previous experiences are the most important factor affecting self-efficacy, individuals with high self-efficacy before training represent a high level of self-efficacy also after training (Tang \& Tseng, 2013). Apart from these factors, various researches have mentioned the impact of other factors, such as age (Kurniawan, Ellis \& Allaire, 2002; Ren, 2000), the education level (Tuncer \& Balci, 2014), academic background (Malliari, Korobili \& Togia, 2012; Ross, Perkins \& Bodey, 2013), access to computers and the internet (Tella, Tella \& Adekunle, 2007; Tella, 2012), computer availability (Ren, 2000), usage frequency (Ren, 2000), English language knowledge (Adalier \& Serin, 2012; Malliari, Korobili \& Togia, 2012), and occupation (Ross, Perkins \&Bodey, 2013).

Despite the importance of the self-efficacy concept in human activities and attention to it in various disciplines over several decades, it has not received much attention from the web research literature. Such negligence can be due to a lack of interdisciplinary research that is observed in most web research efforts. Most educational and practical areas of web research are conditioned and related to human behavior. Areas such as education and information search skills, technology acceptance and application, education and research, organization and retrieval of information are highly dependent on individual behaviors of users and influenced by selfefficacy (Adetoro, Simisaye \& Oyefuga, 2010; Kurniawan, Ellis \& Allaire, 2002). In the related literature, several types of self-efficacy have been investigated that belong to the aforementioned areas and can be used in the web context. Following are some of the most important types of self-efficacy relevant to the web environment:
○ Computer self-efficacy
○ Internet self-efficacy
- Information technology self-efficacy
○ Information literacy self-efficacy
o Information searching self-efficacy
o Social media self-efficacy
$\circ$ Online learning self-efficacy
- Learning Management System (LMS) self-efficacy
○ Academic self-efficacy 


\section{○ Research self-efficacy.}

\section{Computer self-efficacy}

In computer self-efficacy, one's ability to work with a computer individually and the capability of proper use of a computer are more considered (Hasan, 2003; Usluel, 2007). Computer selfefficacy can be applied both to the level of computer-based behavior and to the level of computer use. The relationship between self-efficacy and computer use is clear. Self-efficacy is associated with the enrollment of computer courses and technology adoption. There is a significant relationship between computer self-efficacy and internet self-efficacy. The greater the computer self-efficacy, the greater the internet self-efficacy (Tuncer \& Balci, 2014).

Although individuals with different capabilities in computer use can utilize the internet, it is natural that higher computer self-efficacy leads to better and higher internet use. Computer selfefficacy is more important for children and novices since it would be the base of their skill learning and skill promotion. Therefore, the role of trainers in promoting psychological aspects of computer training is important (Hasan, 2003).

\section{Internet self-efficacy}

Internet self-efficacy contains the ability to send files, email, creating presentation files, software working, use of computer for problem-solving, decision-making, information searching, programming, for which the user should cover a level beyond computer self-efficacy (Tella, Tella \& Adekunle, 2007). Internet self-efficacy also includes familiarity with web design languages, the use of web browsers, transfer of the file to an email, and building a home page (Tella, Tella \& Adekunle, 2007).

The factors affecting internet self-efficacy include age, gender, education level, internet access, and availability of computers (Ata, 2011). Internet self-efficacy varies even among different organizations and individuals. That is, organizations with high self-efficacy use the internet more for search compared to organizations with low self-efficacy (Ren, 1999). With higher computer and internet self-efficacy, the help and direction of users, as well as internet access and use, would be higher.

Self-efficacy regarding internet use is applied to one's belief in his ability in a successful information search and use (Savolainen, 2002). Search findings are the main source of individuals' self-efficacy. Individuals who are less confident in their ability to use the internet are not satisfied with their internet skills, and, conversely, the people have less difficulty in using the internet, they have higher self-efficacy. Of course, people may have high self-confidence but they do not search for information due to lack of motivation. 


\section{Information technology self-efficacy}

Information technology self-efficacy, which is sometimes referred to as ICT self-efficacy, includes network, hardware, software, satellite links and the like converging beyond internet selfefficacy because it includes both hardware and software components (Malliari, Korobili, and Togia, 2012). Information technology self-efficacy may also reduce digital disruption among individuals (Tella, Tella \& Adekunle, 2007). Since knowledge of people on information technology is at different levels and they are not identical, the knowledge level of different individuals can be approached by investigation and enhancement of such self-efficacy (Adetoro, Simisaye \& Oyefuga, 2010).

Information technology self-efficacy and computer competency are positively associated with frequency of use and previous experience. Frequency of use is an important predictor of information technology self-efficacy. It is increased by increasing education levels as well. Research on information technology self-efficacy have mostly been conducted in developed countries (Tuncer \& Balci, 2014), while it is necessary similar research in other countries considering the increased application of such technologies.

\section{Information literacy self-efficacy}

The relationship between computer self-efficacy and information literacy self-efficacy has also been investigated in different works. For example, Ata (2011) found a significant difference between the perception of information literacy self-efficacy, computer availability, frequency of internet and web technologies use, and frequency of their use. Moreover, Ata and Baran (2011) believe that the perception of information literacy self-efficacy varies among students considering computer availability and inter use. Meanwhile, computer self-efficacy directly influences information literacy self-efficacy.

The concept of information literacy self-efficacy is regarded as an integrated concept meaning people's belief in the access, use, sharing, and evaluation of information (Kurbanoglu, Akkoyunlu \& Umay, 2006). Like many skills, a person with information literacy or someone who needs the use of information resources must have a sense of capability in various components of information literacy.

Research has shown that metacognitive strategies, effort management, interpretation, critical thinking, and control beliefs predict different dimensions of information literacy self-efficacy. Learning is structured in such a way that it is mostly autonomous, linked to work and personal life, based on resources, and access to learning resources is important (Kurbanoglu, 2003).

Information literacy self-efficacy is related to all of the above cases and can include some of the components of these cases. Information literacy self-efficacy is a predictor of academic 
achievement (Cakmak, 2010). Moreover, academic motivation is a key factor in the development of information literacy self-efficacy (Savolainen, 2002). Employed or non-employed students do not affect information literacy self-efficacy, although employed studies are more motivated (Ross, 2013). Information literacy self-efficacy is then an important factor in academic achievement, and even it is regarded above logical thinking (Tella, Tella \& Adekunle, 2007).

\section{Information searching self-efficacy}

One of the interesting research findings was discovered by Tella (2009) in which self-efficacy showed the highest and most correlation and impact on the search behavior of students. In other research, it was found that high self-efficacy was more important in finding information rather than the spent time and frequency of searching (Monoi, Hanlon \& Diaz, 2005). Because information searching is one of the major skills of information literacy, it also influences its totality and formation.

Given that approximately 70 percent of students use internet sources than library sources, investigation of different types of self-efficacy especially searching self-efficacy is necessary (Sorapure, Inglesby \& Yatchisin, 1998). Ren (1999) considers information searching selfefficacy as the ability of students to search for resources and information for academic and research purposes. Searching for self-efficacy after training is greater (Hodges \& Murphy, 2009). This increase is related to attitudes, emotional experiences, search performance, and so on. Search performance also affects a student's experience and activities.

Searching self-efficacy is based on the individual's belief in the ability to perform current and future searches, and thus the level of self-confidence of the network competency, and the successful implementation of a set of behaviors for proper use of the internet in the information searching (Monoi, Hanlon \& Diaz, 2005). Self-efficacy is more important to newcomers as it is very important at the beginning of working with the network. Understanding situation and operational goals, rules of selection of different channels, awareness of information resources, and awareness of obstacles to internet access are among the factors affecting information searching self-efficacy. The relationship between intellectual, emotional, and perceptional processes has valuable points for understanding information searching behavior.

Information searching self-efficacy is directly correlated with information manipulation selfefficacy and internet learning self-efficacy (Tang \& Tseng, 2013). Related research has indicated that searchers with high self-efficacy more use databases and digital libraries. While searchers with low self-efficacy use search engines such as Google and Yahoo (Tella, Tella \& Adekunle, 2007), searchers with high self-efficacy use electronic resources better and more. Students with high educational self-efficacy use more effective learning strategies (Kurbanoglu, 2003). If people feel competent and confident in information searching skills, they use the information for 
problem-solving activities better and would turn into self-regulatory learners (Cabaroglu, 2014; Kurbanoglu, Akkoyunlu \& Umay, 2006).

In research by Malliari, Korobili, \& Togia (2012), it was found that searching self-efficacy was strongly influenced by purchase decisions and satisfaction with online shopping. The previous search experiences and learning before searching affect searching self-efficacy. For example, students' self-efficacy in internet information searching after training is quite higher. In the discussion of searching self-efficacy, the frequency of use, experience, and previous knowledge should be considered (Figure 4).

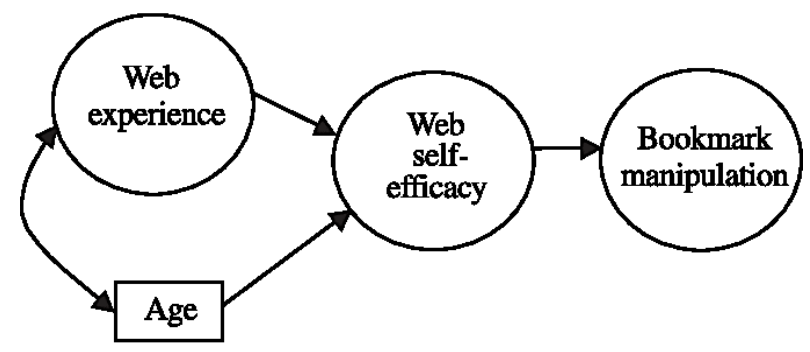

Figure 4. Web self-efficacy and searching behavior of users (Kurniawan, Ellis \& Allaire, 2002)

This increase is related to attitudes, emotional experiences, search performance, and so on. Searching performance influences a student's experience and activity. According to Ata (2011), inefficiency in information searching is related to low self-efficacy. Individuals with average to high self-efficacy participate more in searching for strategies. There is a direct relationship between the use of an information source and self-efficacy. Homework, computer use, and the degree of self-efficacy are the factors affecting the use of electronic library resources by students. Specifically, information searching self-efficacy may directly affect the self-confidence of students, and subsequently influence their learning and performance (Ross, Perkins \& Bodey, 2013).

\section{Social media self-efficacy}

As an identified variable in related literature, media self-efficacy could also be addressed in the web environment in a form like social media self-efficacy. Media self-efficacy is considered as a person's perceptions of how to perform a task like gathering information from the media to fulfill correspondent personal needs by using different media like television, newspapers or interpersonal communication (Hofstetter, Zuniga \& Dozier, 2001). As a result, a person's beliefs about his or her capabilities to perform desired functions specifically in the social media environment could be coined as social media self-efficacy (Hocevar, Flanagin \& Metzger, 2014).

A person's self-efficacy with the internet generally may differ from perceived efficacy with social media and should be distinguished from it. Thus, drawing from Bandura's theory of the sources of information that inform self-efficacy judgments, social media self-efficacy is based 
upon a person's level of social media content production and consumption, perceived social media skill, and confidence in his or her ability to successfully find information online. Moreover, social media users should have more experience with social information sources via enactive mastery experience and vicarious experience than those lower in social media selfefficacy (Hocevar, Flanagin \& Metzger, 2014). These users are therefore likely to be more familiar with such sources than those lower in social media efficacy.

\section{Online Learning Self-Efficacy}

Self-efficacy has been shown by numerous researchers to be a valid measure related to increased probabilities that individuals will successfully perform the required tasks in academic domains. If instructional programs in higher education can contribute to increased self-efficacy for learners as they negotiate the new task domain of online learning, learners are increasingly likely to persevere and achieve their higher education goals in complement with the institutions' technologies. This suggests that an intervention's impact upon commencing learners' online learning self-efficacy may be a key to its effectiveness.

The role of self-efficacy in online learning environments is of great importance and a pressing need for new instructional purposes. Through exploratory factor analysis, Shen, Cho, Tsai and Marra (2013) identified five dimensions of online learning self-efficacy: (a) self-efficacy to complete an online course, (b) self-efficacy to interact socially with classmates, (c) self-efficacy to handle tools in a Course Management System (CMS), (d) self-efficacy to interact with instructors in an online course, and (e) self-efficacy to interact with classmates for academic purposes. Such a conceptualization could bring us new insights as to how much self-efficacy and online learning are interrelated.

\section{LMS self-efficacy}

Online courses and Learning Management Systems (LMS) have received a great deal of attention in the last few years. Research indicates learner self-efficacy with LMS may be a critical factor in e-learner satisfaction (Lee \& Hwang, 2007) and performance. LMS selfefficacy, defined as self-assessment regarding one's skills using an LMS, maybe a critical factor in e-learner satisfaction.

Martin and Tutty (2008) and Martin et al. (2010) have developed an instrument to measure LMS self-efficacy, this instrument measures the confidence levels of learners with LMS and how it affects their performance. The instrument includes five technology parts: (1) assessing the course content, (2) tests and grades, (3) asynchronous communication, (4) synchronous communication, (5) Advanced tools. They found that the self-efficacy of online learners was significantly higher than hybrid learners. However, LMS self-efficacy does not have a significant effect on-course 
performance for the online learners but it had a positive influence on-course performance for the hybrid learners.

\section{Academic self-efficacy}

Self-efficacy is one of the factors affecting academic and educational self-efficacy enriched by the use of web facilities (Adalier \& Serin, 2012; Cabaroglu, 2014) known as academic selfefficacy. Self-efficacy research is prevalent in educational research, especially in studies of academic motivation and self-regulation. Self-efficacy beliefs are correlated with motivational structures and educational performance. The motivational level of learners is considered the most important factor in successful education (Multon, Brown \& Lent, 1991). Targeting, modeling, problem-solving, test anxiety, reward, self-regulation, and social comparison have been reported as having a positive correlation with self-efficacy (Cakmak, 2010).

As a psychological factor, self-efficacy affects the outcomes of students and it is a construct that changes with the acquisition of new experiences and knowledge over time (Malliari, Korobili, \& Togia, 2012). The significance of self-efficacy is student population and different learning areas have been considered. Self-efficacy, distance learning, self-regulated learning, and information literacy skills are the main predictors for online learning (Bates \& Khasawneh, 2007; Tella, Tella \& Adekunle, 2007).

In the meta-analysis by Multon, Brwon and Lent (1991) a relationship between self-efficacy beliefs and academic performance was observed. According to research findings (e.g., Ross, Perkins \& Bodey, 2013; Tang \& Tseng, 2013; Tella, Tella \& Adekunle, 2007), the predictive power of self-efficacy on students' educational performance can be extensively confirmed. Students with high academic self-efficacy use more effective learning strategies. Various studies have pointed out the fact that students' self-efficacy beliefs have a meaningful and positive relation to their academic performance connected with the web facilities.

\section{Research self-efficacy}

Self-efficacy influences methodology and research method selection as well as research implementation through web tools and facilities (Arslan, 2017; Artino, 2012). Individuals with high self-efficacy show higher self-efficacy in research subject and methodology selection and research implementation including finding a problem, data collection, data analysis, and conclusion and writing research (Baltes et al., 2010). High self-efficacy influences interest in research, increased scientific products (Hemmings \& Kay, 2010), and low self-efficacy leads to a lack of interest and a lack of scientific achievements. Different researchers have proposed almost similar components for research self-efficacy. Most of them are related to the scientific processes of research. For example, Arsalan (2017) reviewed related literature and identified seven types of statistical and analytical self-efficacy, conceptualization, method and implementation, qualitative 
research, report writing, skills, and ultimately the ethics. While Artino (2012) considered four types of self-efficacy including practical research skills, writing skills, research design skills, and computer and quantitative skills. Therefore, the role of web instructors in the research process and helping researchers can be manifested in making ground for psychological conditions and increasing their self-efficacy.

One of the main problems of experts and researchers is a lack of self-confidence and necessary self-efficacy for professional research through the web environment (Hemmings \& Kay, 2010). Such a lack of self-efficacy results from a lack of required knowledge and competency. An interested or talented researcher might not be able to optimally accomplish given research because of a lack of belief in the ability to utilize the web. Such a problem, on one hand, maybe the basis for researching in the self-efficacy area, and, on the other hand, it may increase the attention of research method trainers and the researchers themselves to the psychological aspects of research.

\section{Web self-efficacy and web literacy}

Information search is one of the highly applied areas in web usage. It not only requires studying this issue but also makes it a serious research area (Kurniawan, Ellis \& Allaire, 2002; Rodon and Meyer, 2018). Such a situation causes reviewing description and definition of information literacy so that not only information literacy has gone beyond a framework merely based on the skill but also its formation is considered an indirect relationship with the information search environment. Thus, a new concept known as web literacy originating from such perspectives to information literacy is worth discussing, which considers the web as an information environment being influenced by social, psychological factors. There seems to be a pressing need to develop such a web literacy approach especially with the emergence of technologies like social software, wikis, blogs, open-source systems and what is known as the web 2.0 movement.

According to Sorapure, Inglesby, and Yatchisin (1998), the web as an information source has always two major challenges: modes of writing, and meta-textural nature, and multi-media resources. Thus, web literacy is identified as ability and extensive evaluation of web characteristics and attention to available information in the source's non-textual features. Webliteracy is mostly based on processes of resource evaluation obtained through searching. Web literacy training means providing evaluation rules that traditionally are used about printed resources, as well as presenting strategies for understanding various types of resources provided in meta-textual and multi-media forms. Evaluation of web resources not only increases the ability of users and the quality of their intellectual products but also improves the web itself.

Although there is no single set of criteria for evaluating web resources and even printed material. However, with an emphasis on misinformation and disinformation resources, it is possible to 
classify proposed criteria in structural and content classes. Of course, it should be noted that most of these criteria are so that include both aspects and considering them requires both structural and content views. From a structural perspective, many criteria have been provided by researchers.

A review of research backgrounds suggests a relationship between web skills and psychological components such as self-efficacy. In other words, web literacy skills are required for the optimal application of the web in daily life and work. Users just by relying on their technical skills cannot have a successful application of the web environment. Psychological skills such as web self-efficacy are required for a successful web application.

\section{Conclusion}

Attention to the concept of self-efficacy in scientific research has been confirmed by different researchers, and its intervention in most human behaviors has been approved. Concerning the professional and environmental changes in the web context in which the use of new tools and technologies has become important and users have gained more and more important roles, it is desirable to examine this concept in the behavioral areas such as web literacy. The presence of information technology, computers, and the internet has influenced many of the activities of this field. Therefore, self-efficacies related to them can be reviewed based on users' behaviors and actions. Besides, the assistant role of the web in education and research leads to improved selfefficacies related to information searching, social media, learning, education, and research.

\section{References}

Arslan, A. (2017). Investigation of listening anxiety and academic self-efficacy beliefs of secondary school students in terms of various variables. International e-Journal of Educational Studies, l(1), 12-31.

Artino, A. R. (2012). Academic self-efficacy: from educational theory to instructional practice. Perspectives on Medical Education, 1, 76-85.

Ata, F. (2011). The investigation of correlation between the undergraduate students' usage of eb 2.0 technology and perceptions of information literacy self-efficacy. Master's Thesis, Dokuz Eylül University Institude of Educational Sciences, İzmir.

Ata, F., \& Baran, B. (2011). Investigation of undergraduate students' information literacy selfefficacy according to foreign language level, gender, computer ownership and the internet connection duration. 5th International Computer \& Instructional Technologies Symposium (pp. 22-24). Elazı̆g- Turkey: Firat University.

Adalier. A., \& Serin. O. (2012). Teacher candidates' information literacy self-efficacy. Online Journal of Science and Technology, 2(2). Retrieved January 15, 2020, from http://www.tojsat.net/index.php/tojsat/article/view/44/50 
Adetoro, N., Simisaye, A. \& Oyefuga, A. (2010). Relationship between Perceived Self-Efficacy and Information Literacy among Library and Information Science Undergraduates in a Nigerian University of Education. IFE PsychologIA, 18(2). Retrieved January 15, 2020, from https://www.ajol.info/index.php/ifep/article/view/56758

Baltes, B., Kipp, P., Lynn, L., \& Weltzer, L. (2010). Students' research self-efficacy during online doctoral research Courses. Contemporary Issues in Education Research, 3(3), 51-57.

Bandura, A. (1977). Self-efficacy: The exercise of contro. New York, NY: Freeman.

Bandura, A. (1986). Social foundations of thought and action: A social cognitive theory. Prentice-Hall: Englewood Cliffs.

Bandura, A. (1993). Perceived self-efficacy in cognitive development and functioning. Educational Psychologist, 28, 117-148.

Bandura, A. (2001). Social cognitive theory: An generic perspective. Annual Review of psychology, $52,1-26$.

Bates, R., \& Khasawneh, S. (2007). Self-efficacy and college students' perceptions. Computers in Human Behavior, 23, 175-191.

Cabaroglu, N. (2014). Professional development through action research: Impact on self-efficacy. System, 44, 79-88.

Cakmak, E. (2010). Learning strategies and motivational factors predicting information literacy selfefficacy of e-learners. Australasian Journal of Educational Technology, 26(2), 192-208.

Haggbloom, S. J. (2002). The 100 most eminent psychologists of the 20th century. Review of General Psychology, 6(2), 139-152.

Hasan, B. (2003). The influence of specific computer experiences on computer self-efficacy. Computers in Human Behavior, 19(4), 443-50.

Hemmings, B. C., \& Kay, R. (2010). Research self-efficacy, publication output and early career development. International Journal of Educational Management, 24(2), 562-574.

Hocevar, K. P., Flanagin, A. J., \& Metzger, M. J. (2014). Social media self-efficacy and information evaluation online. Computers in Human Behavior, 39, 254-262.

Hodges. C., \& Murphy, P. (2009). Sources of self-efficacy beliefs of students in a technologyintensive asynchronous college algebra course. Internet \& Higher Education, 12, 93-97.

Hofstetter, C. R., Zuniga, S., \& Dozier, D. M. (2001). Media self-efficacy: Validation of a new concept. Mass Communication and Society, 4, 61-76

Jääskeläinen, P. \& Savolainen, R. (2003). Competency in network use as a resource for citizenship: implications for the digital divide. Information Research, 8(3), paper 153. Retrieved January 15, 2020, from http://informationr.net/ir/8-3/paper153.html

Kurbanoglu, S. (2003). Self-efficacy: A concept closely linked to information literacy and lifelong learning. Journal of Documentation, 59(3), 635-646. 
Kurbanoglu, S., Akkoyunlu, B., \& Umay, A. (2006). Developing the information literacy self-efficacy scale. Journal of Documentation, 62, 730-743.

Kurniawan, S. H., Ellis, R. D., \& Allaire, J. C. (2002). The impact of Web self-efficacy, age, and web experience on bookmark manipulation. Universal Access in the Information Society, 1(3), 207216.

Lee, J. K., \& Hwang, C.Y. (2007). The effects of computer self-efficacy and learning management system quality on e-Learner's satisfaction. In Cameron, L., Voerman, A. \& Dalziel,J. (Eds), Proceedings of the 2007 European LAMS Conference: Designing the future of learning (pp7379). 5 July. Greenwich: LAMS Foundation.

Malliari, A., Korobili, S., \& Togia, A. (2012). IT self-efficacy and computer competence of LIS students. The Electronic Library, 30(5), 608-622.

Martin, F., Tutty, J. I., \& Su, Y. (2010). Influence Of Learning Management Systems Selfefficacy On E-Learning Performance. imanager's Journal on School Educational Technology, 5(3), 26-35.

Monoi, S., Hanlon, N., \& Diaz, K. (2005). Online searching skills: Development of an inventory to assess self-efficacy. Journal of Academic of Librarianship, 31, 98-105.

Multon, K. D., Brown, S. D., \& Lent, R. W. (1991). Relation of self-efficacy beliefs to academic outcomes: A meta-analytic investigation. Journal of Counseling Psychology, 38, 30-38.

Pajares, F. (1997). Current directions in self-efficacy research. In Maehr. M., \& Pintrich P. R. (Eds.), Advances in motivation and achievement (10, 1-49). Greenwich: JAI Press.

Ren, W. (1999). Self-efficacy and the search for government information: A study. References and User Services Quarterly, 38, 283-291.

Ren, W. (2000). Library instruction and college student self-sufficiency in electronic information searching. Journal of Academic of Librarianship, 26(5), 323-328.

Rodon, C., \& Meyer, T. (2018). Self-efficacy about information retrieval on the web across all domains: A short measure in French and English. Behavior \& Information Technology, 37(5), 430-444.

Ross, M., Perkins, H., \& Bodey, K. (2013). Information literacy self-efficacy: The effect of juggling work and study. Library and Information Science Research, 35, 279-287.

Savolainen, R. (2002). Network competence and information seeking on the Internet: from definitions towards a social cognitive model. Journal of Documentation, 58(2), 211-226.

Shen, D., Cho, M. H., Tsai, C. L., \& Marra, R. (2013). Unpacking online learning experiences: Online learning self-efficacy and learning satisfaction. The Internet and Higher Education, 19, 10-17.

Sorapure. M., Inglesby. P., \& Yatchisin. G. (1998). Web literacy: Challenges and opportunities for research in a new medium. Computers and Composition, 15, 409-424.

Tang, Y., \& Tseng, H. (2013). Distance learners' self-efficacy and information literacy skills. The Journal of Academic Librarianship, 39, 517-521. 
Tella, A. (2009). Correlates of undergraduates' information seeking behavior. College and Undergraduate Libraries, 16(1), 1-19.

Tella, A., Tella, A., Ayeni, C. O., \& Omoba, R. O. (2012). Self-efficacy and use of electronic information as predictors of academic performance. Retrieved January 15, 2020, from http://southernlibrarianship.icaap.org/content/v08n02/tella_a01.html

Tella, A., Tella, A., \& Adekunle, P. (2007). An assessment of the librarian social competence and ICT's self-efficacy: Implications on the library practices in the digital era. Pacific Northwest Library Association Journal, PNLA Quarterly, 71(4), 12-16.

Tuncer, M., \& Balci, K. (2013). The research of the effect of computer and information literacy selfefficacy on the achievement of information literacy. Journal of Studies in Education, 3(4). Retrieved January

15 , 2020 ,

from http://www.macrothink.org/journal/index.php/jse/article/view/4212/3620

Usluel, Y.K. (2007). Can ICT usage make a difference on student teachers' information literacy selfefficacy. Library \& Information Science Research, 29, 92-102.

\section{Bibliographic information of this paper for citing:}

Keshavarz, H. (2020). "Web self-efficacy: A psychological prerequisite for web literacy." Webology, 17(1), Article 209. Available at: http://www.webology.org/2020/v17n1/a209.pdf 